\title{
Clinical Profile of Pediatric Alopecia Areata in Faisalabad City
}

\author{
Muhammad Arif Maan¹, Ayesha Abrar², Hoda Zahoor 3 , Fatma Hussain 4 , Shahid Javaid Akhtar ${ }^{5}$ \\ 1,5Department of Dermatology, Faisalabad Medical University, Faisalabad-Pakistan, ${ }^{2 D e p a r t m e n t ~ o f ~ D e r m a t o l o g y, ~ G h u l a m ~ M u h a m m a d ~ G e n e r a l ~ H o s p i t a l, ~ F a i s a l a b a d-P a k i s t a n, ~}$ \\ 3,4Department of Biochemistry, Faisalabad Medical University, Faisalabad-Pakistan,
}

\section{ABSTRACT}

Background: Alopecia areata is the most prevalent inflammatory disease involving a non-scarring type of hair loss. Objective: The current study was undertaken to evaluate the clinical features of pediatric alopecia areata among the local population of Faisalabad. Study Design: Cross-sectional study. Settings: Government General Hospital, Ghulam Muhammad Abad, Faisalabad. Duration: From March 2019 to August 2019. Methodology: By convenient sampling technique, fifty patients diagnosed by a physician were recruited and baseline information such as age, age at onset, sites affected, the severity of the disease, associated diseases, and family history were recorded. Data were expressed in continuous variables by using the mean standard deviation (SD) method. Categorical variables were used to enlist and document data by using frequencies. Results: The mean age at onset was $4.3 \pm 0.72$ years and $7.1 \pm 0.05$ years in the case of girls and boys respectively. With the male to female ratio of 1.17:1, PAA was more prevalent among boys. It mainly targeted the scalp region ( $p$ value $=0.043$ ) that is up to $98 \%$ of patients along with the deterioration of eyebrows, eyelashes, and whole-body hairs. One-fourth cases under study had a significant positive family history for psoriasis $(p$ value $=0.048)$ and atopic disorders had a significant association with alopecia areata $(p$ value $=0.032$ ). Conclusion: The study inferences are male predominance, mild manifestations in the scalp region, and positive family history for psoriasis suggesting underlying genetic background. Atopic disorders were found to be commonly associated with AA. Further studies with a large sample size should be executed to evaluate its clinical profile properly.

Keywords: Alopecia areata, Alopecia totails, Pathogenesis.

\begin{tabular}{l} 
Corresponding Author \\
$\begin{array}{l}\text { Submitted for Publication: 29-03-2020 } \\
\text { Dr. Fatma Hussain, Associate Professor, Biochemistry, University of Agriculture, Faisalabad-Pakistan } \\
\text { Email: fatmauaf@yahoo.com }\end{array}$ \\
\hline Citation: Maan MA, Abrar A, Zahoor H, Hussain F, Akhtar SJ. Clinical Profile of Pediatric Alopecia Areata in Faisalabad City. APMC 2020;14(1):233- \\
6. \\
DOI: $10.29054 / A P M C / 2020.766$
\end{tabular}

\section{INTRODUCTION}

Alopecia Areata (AA) in children is an autoimmune disease, which is associated with inflammatory responses characterized by T-cells targeting the nails and hair follicles. It leads to hair loss, resulting in small patches of baldness on the scalp, face, and the whole body. It equally affects all ages, genders, and skin types. Children of all ages are affected by this disease. This largely affects boys physically. ${ }^{1,2}$ The most common causes of Pediatric Alopecia Areata (PAA) is non-scarring hair loss. ${ }^{3}$ The cases of atopy, nail destruction and about twenty related syndromes caused by pediatric AA have been reported. ${ }^{4}$ Based on the difference in the appearance of patches, $A A$ is divided into different subtypes which are ophiactids, sudden graying type, diffuse form, and sisaipho. 5,6

Regardless of sex discrimination, the lifetime prevalence of $A A$ is approximately $20 \%$. Typically, patients with age above 40 years are mostly affected by this disease. ${ }^{7}$ The life span prevalence among USA and UK populations is $2 \%$ and the estimated occurrence is 0.1 to $0.2 \%{ }^{8}$ Both in Singapore and India about one-third of persons affected by AA were below the age of 20 years. In Pakistan, about $22 \%$ of patients were affected by AA according to a study. ${ }^{9}$

The progressiveness of $A A$ is not predictable. Sometimes hair regrows after the first attack of $A A$ but relapses of $A A$ are observed. About $70-80 \%$ of patients experience recovery and hair growth is initiated. Due to successful recovery, $A A$ is known as short term transient condition. Although genetic predisposition can commence the highest degree of AA leading to intense hair loss. ${ }^{10}$

PAA is a multifactorial disease with both genetic and immune components involved. However, its exact cause is not known yet. During the growth phase, the lower bulb of the hair follicle is surrounded by infiltrate of cytotoxic T cells. T helper (Th) and plasmacytoid dendritic cells damage hair follicles by autoimmune reactions. The main cell type which begins this procedure is cytotoxic $T$ cells. Interferon $y$ (IFNy) produced by $T$ helper 1(Th1), T helper 17(Th17), natural killer (NK) and CD8+ cells, cause the vandalization of hair follicles, hair growth phases, resulting in loss and termination of their growth. ${ }^{10,11}$

PAA is a non-scarring loss of hair in children of all ages. It is reported to be more prevalent among Kuwait and Singapore populations. In Kuwait, it is the third most common dermatosis based upon recruitment percentage (6.7\%). However, it is less observed among children of Arab ancestry. ${ }^{12}$ A study was carried out for evaluation of prevalence and a common reason for hair fall among the children in Karachi, Pakistan from October to December 2014 by using simple sampling techniques. It was observed that $73.5 \%$ of the population had a hair fall problem. ${ }^{13}$ According to another study carried out at Hamdard University Hospital, Karachi, a total of 830 cases were recruited for pediatric dermatosis however PAA was observed in very low frequency in comparison to other dermatoses.$^{14}$ 
Various therapeutic approaches including topical, injective, and systemic are being used. Corticosteroids are the most common type of therapy used to cure disease. A high level of antiinflammatory effects is shown by glucocorticoid treatment. Corticosteroids can be introduced by topical, injection, or by the systemic method. The first line of treatment includes intralesional corticosteroids for less severe AA. Corticosteroids are less effective but still used because of its safety profile. ${ }^{15}$ Currently used alternative treatments are the use of bimatoprost as an analog of prostaglandin ${ }^{16}$, phototherapy ${ }^{17}$, cryotherapy ${ }^{18}$, and tofacitinib as JAK inhibitor. ${ }^{19,20}$

As in the Faisalabad region, only limited data is available regarding PAA prevalence, demographic, and associated factors, therefore the current study was conducted to assess the clinical perspectives in the local population of Faisalabad.

\section{METHODOLOGY}

Study Design: Cross-sectional study.

Settings: Government General Hospital, Ghulam Muhammad Abad, Faisalabad Pakistan.

Duration: March 2019 to August 2019.

Sample Technique: Easily accessible techniques.

Sample Size: 50 patients.

Inclusion Criteria: Male and female children with less than sixteen years of age, having physician-diagnosed active AA who gave consent for the study were included.

Exclusion Criteria: All patients with greater than 16 years of age, who refused to give consent for the study and having any cause of hair loss other than alopecia areata were excluded.

Data Collection Procedure: Before recruitment, each subject was given a brief guideline about the purpose of the study. PAA was diagnosed by previously designed method ${ }^{21}$ based on the usual history of patchy, abrupt loss of hairs with or without progression and completely fine-looking scalp. The data of demographic parameters such as gender, age, age at the time of onset, duration of PAA, site of PAA onset, affected sites, severity, and associated diseases with special accordance with thyroid diseases, atopic disorders, psoriasis and family history was recorded. The sample was further divided into subgroups. The patients were classified according to age groups: infancy (0-2 years), preschool period (3-5 years), school period (6-11 years), and adolescent period (12-15 years). To evaluate the severity level of $A A$, children were divided into three groups, mildly affected, moderately affected, and severely affected. Physical examination of all the patients was done by dermatologists after the informed consent of each patient. Physical examination of all the patients was done by dermatologists after informed consent of each patient.

Data Analysis: After collection, data was analyzed and recorded. Mean standard deviation (SD) was used to express the data in continuous variables. Categorical variables were used to enlist and document data by using frequencies. By using Statistical Package for Social Sciences (version 17; Chicago, USA), collected information was analyzed by the Chi-square test. Differences in variable parameters were evaluated and the $P$ value that was considered significant was $<0.05$.

\section{RESULTS}

A total of 50 children recruited, with males to the female proportion of 1.17 to 1 (Table 1). The number of boys affected was slightly higher than the girls. Averaged age was $7.5 \pm 0.98$ years and the youngest child was only six months of age, while the maximum age of the patient was 15 years. Age at onset of PAA was $7.1 \pm 0.05$ years and $4.3 \pm 0.72$ years in boys and girls respectively.

Among the associated diseases, atopic disorders were significantly associated ( $p$ value $=0.032$ ) as reported in 45 patients $(90 \%)$ followed by vitiligo in 2 patients (4\%) and psoriasis in 3 patients $(6 \%)$.

Table 1: Clinical Profile of Pediatric Alopecia Areata $(n=50)$

\begin{tabular}{|l|l|l|}
\hline Clinical parameters & Frequency \\
\hline \multirow{3}{*}{ Gender } & Male (M) & 27 \\
& Female $(\mathrm{F})$ & 23 \\
& M: F ratio & $1.17: 1$ \\
\hline Mean age at onset & Male & $7.1 \pm 0.05$ \\
(years) & Female & $4.3 \pm 0.72$ \\
\hline \multirow{5}{*}{ Site of AA onset } & Scalp & $49^{*}$ \\
& Eyebrows & 0 \\
& Eyelashes & 1 \\
& Body hairs & 0 \\
\hline \multirow{5}{*}{ Associated diseases } & Atopic disorders & $45^{*}$ \\
& Autoimmune diseases & 0 \\
& Thyroid disease & 0 \\
& Vitiligo & 2 \\
& Psoriasis & 3 \\
& Lichen planus & 0 \\
& Down syndrome & 0 \\
\hline
\end{tabular}

Data presented as number $(\mathrm{n})$, mean \pm Standard deviation (SD), *P value $<0.05$

Out of 50 patients, 8 were infants, 10 were in the preschool stage, 27 attending school, and 5 were adolescents (Table 2).

Table 2: Age - wise distribution of sample

\begin{tabular}{|c|c|c|c|c|c|}
\hline $\begin{array}{c}\text { Age } \\
\text { Range } \\
\text { (Min.- } \\
\text { Max.) }\end{array}$ & $\begin{array}{c}\text { Mean } \\
\text { Age } \\
\text { (years) }\end{array}$ & $\begin{array}{c}\text { Infants } \\
\text { (n) }\end{array}$ & $\begin{array}{c}\text { Preschool } \\
\text { (n) }\end{array}$ & $\begin{array}{c}\text { School } \\
\text { goers }(\mathbf{n})\end{array}$ & $\begin{array}{c}\text { Adolescents } \\
\text { (n) }\end{array}$ \\
\hline $\begin{array}{c}6 \text { months } \\
-15 \text { years }\end{array}$ & $\begin{array}{c}7.5 \pm \\
0.98\end{array}$ & 8 & 10 & 27 & 5 \\
\hline
\end{tabular}

Data presented as number ( $\mathrm{n}$ ), mean \pm Standard deviation (SD)

The degree of severity of PAA varied among all the patients. About $64 \%$ showed mild AA condition whereas $10 \%$ exhibited severe manifestations (Table 3).

Table 3: Severity of Alopecia areata

\begin{tabular}{|l|c|}
\hline \multicolumn{1}{|c|}{ Scale } & Participants $(\mathbf{n})$ \\
\hline Mild & $32^{*}$ \\
\hline Moderate & 13 \\
\hline Severe & 5 \\
\hline
\end{tabular}

Data presented as number (n), ${ }^{*} \mathrm{P}$ value $<0.05$ 
According to this study, the common site of onset and mostly affected part was the scalp region in about $98 \%$ participants ( $p$ value $=0.043$ ). About $68 \%$ of children lost all their scalp hairs. PAA was restricted to eyebrows in 2 patients (4\%), eyelashes in $1(2 \%)$, along with $8(16 \%)$ patients with both scalp and eyebrows, $1(2 \%)$ with scalp and eyelashes, $1(2 \%)$ with the scalp, eyelashes, body hairs and eyebrows, $3(6 \%)$ patients with eyelashes, body hairs and scalp (Figure 1 ).

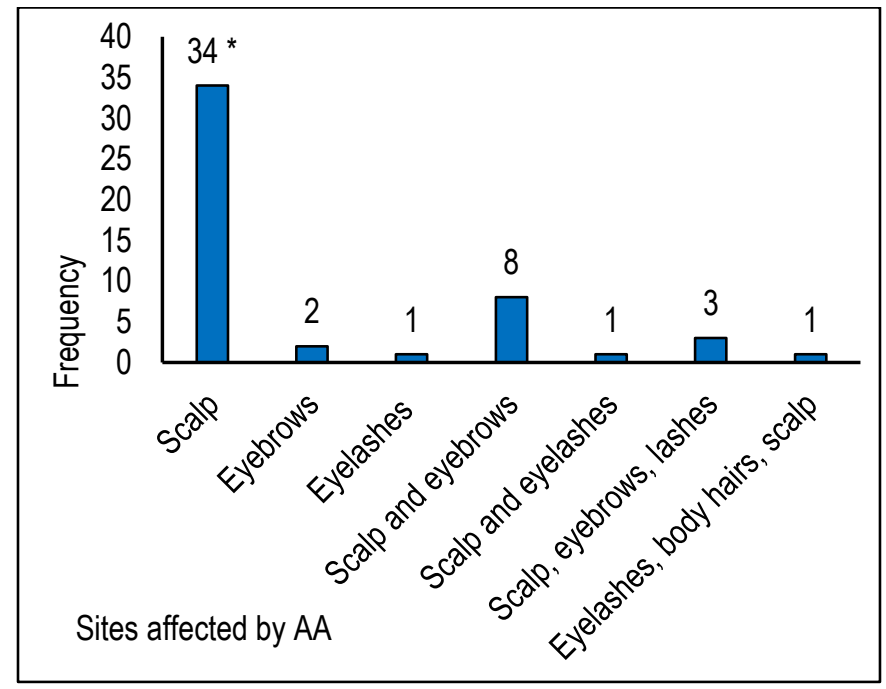

Figure 1: Sites affected by Alopecia areata

Data presented as number (n), ${ }^{*} \mathrm{P}$ value $<0.05$

The highest number (44\%) of children had a family history of psoriasis ( $p$ value $=0.048$ ). Whereas, $24 \%$ of children had a family history of AA. Thyroid and vitiligo were reported in families of $10 \%$ and $22 \%$ of children respectively (Figure 2 ).

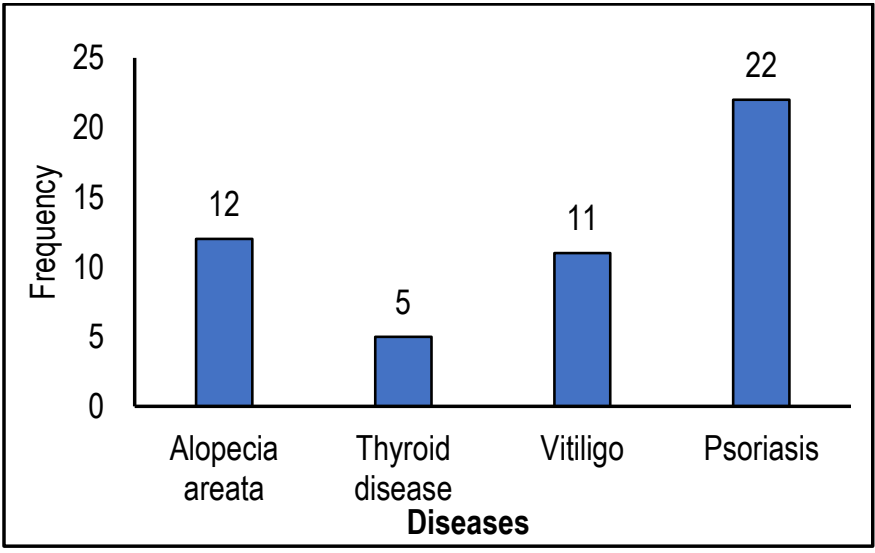

Figure 2: Family history of participants

\section{DISCUSSION}

The dermatological unit of Government General Hospital, Ghulam Muhammad Abad, Faisalabad recruited 50 children with age range 6 months- 15 years to assess the salient features of AA. Out of 50 patients, $16 \%$ were infants, $20 \%$ were in the preschool stage, $54 \%$ attending school, and $10 \%$ were adolescents. This is comparable to earlier studies conducted in Kuwait ${ }^{12}$, Turkey ${ }^{22}$, Singapore ${ }^{23}$, and India. ${ }^{24}$ Mostly Pediatric
AA is observed among the children having age greater than 2 years as reported earlier by Polat and his colleagues that only $17 \%$ were under the age of 2 years. ${ }^{22}$

The current study elucidated that PAA is slightly more prevalent among boys than girls in contrary to a study conducted by Sharma and his colleagues, indicating female predominance by $46 \%$ girls comparable to only $19 \%$ boys. ${ }^{24}$ However, a study conducted in Pakistan by Ejaz and his colleagues elucidated gender equality in PAA affected samples. ${ }^{9}$

Current data reflected a greater proportion of children between the ages of 4-7 years at the onset of PAA. In contrast to this, the previous report elucidated that a greater proportion of children show the onset of PAA at infancy. ${ }^{19}$ Earlier study ${ }^{25}$ reported the loss of body hairs in $72 \%$ children along with major nail dystrophy. Whereas, in current research most commonly affected site was scalp followed by eyelashes, body hairs, and eyebrows. Some children had more than one site affected. About $4 \%$ of children with alopecia had affected eyebrows and eyelashes. Some had lost all their body hairs, eyelashes, eyebrows, and scalp hairs. This difference in the sites affected might be due to varying environment, genetic factor and lifestyle. ${ }^{25}$ All the PAA patients showed varying degrees of severity. The highest percentage of participants exhibited mild PAA manifestations. Although, severely affected children were $10 \%$. Review of literature revealed that up to $26 \%$ of PAA patients can have severe symptoms. ${ }^{26}$

Variable severity levels among different reports may be due to variations in lifestyle, environmental, social issues, age, and genetic factors. Atopic disorders being the most common in the community showed a greater association with $A A$ as reported earlier. ${ }^{9,27}$ Atopic disorders had been reported to be associated with AA in $90 \%$ of patients followed by the association with vitiligo and psoriasis in accordance with another report. ${ }^{9}$ Contrary to previously reported results ${ }^{9}$ thyroid disease was not observed in PAA patients.

A positive family history of PAA in $24 \%$ of children in our study was higher than that reported by three studies from Singapore ${ }^{23}$, India ${ }^{24}$, and China. ${ }^{28}$ Nonetheless, $51.6 \%$ of Kuwaiti children had a positive family history. ${ }^{12}$ In accordance with previously reported study ${ }^{12}$ family history of other associated diseases like psoriasis was much higher in PAA children.

\section{CONCLUSION}

PAA is continuously deliberating disease which is found to be caused by genetic and immunological factors. PAA, being the third most prevalent dermatosis, had affected both genders and highlighted the current scenario in the local population of Faisalabad. As per our knowledge, no population-based work has been done so far among the local population of Faisalabad as we have reported. Further studies with a large sample size are warranted to elucidate the clinical spectrum and underlying pathophysiological mechanism of PAA in Faisalabad city.

\section{LIMITATIONS}

Dimensions of current study could be considered a limitation. Large sample size could elaborate more knowledge. Inclusion 
of clinical assessments and treatment options available/used might highlight severity status and patient's compliance with therapy.

\section{SUGGESTIONS / RECOMMENDATIONS}

It is suggested that community awareness campaign should be launched regarding pediatric alopecia areata and related skin diseases. Educational programs in school may provide better understanding of PAA. Pre-marital genetic counselling should be practiced to eradicate burden of hereditary dermal manifestations. Large sample size studies with blood and skin sampling for pathophysiological understanding of inflammatory and immunological causative factors should be conducted to verify findings of the current study.

\section{CONFLICT OF INTEREST / DISCLOSURE}

There is no conflict of interest involved.

\section{ACKNOWLEDGEMENTS}

The authors thank Dr. Khurram Shahzad, Consultant Dermatologist, Faisalabad Medical University, Faisalabad for his invaluable help during data collection.

\section{REFERENCES}

1. Christensen H, Yang JH, Soccio LC. Bullying and Quality of Life in Pediatric Alopecia Areata. Skin Appendage Disord. 2017;3(3):115-18.

2. Hordinsky MK. Overview of Alopecia Areata. J Investig Dermatol Symp Proc. 2013;16(1):13-5.

3. Cranwell W, Sinclair R. Common causes of pediatric alopecia. Aust J Gen Pract. 2018;47(10):692-6.

4. Wang E, Lee JSS, Tang M. Current treatment strategies in pediatric Alopecia Areata. Indian J Dermatol. 2012;57(6):459-65.

5. Finner AM. Alopecia areata: Clinical presentation, diagnosis, and unusual cases. Dermatol Ther. 2011;24(3):348-54.

6. Strazulla LC, Wang EH, Avila L, Sicco KL, Brinster, N, Christiano $A M$, et al. Disease characteristics clinical evaluation and new perspective on pathogenesis. J Am Acad Dermatol. 2017;78(1):1-12.

7. Korta DZ, Christiano AM, Bergfeld W. Alopecia areata is a medical disease. J Am Acad Dermatol.2018;78(4):832-4.

8. Strazulla LC, Wang EH, Avila L, Sicco KL, Brinster, N, Christiano $A M$, et al. An appraisal of new treatment approaches and overview of current therapies. J Am Acad Dermatol. 2018;78(1):15-24.

9. Ejaz A, Jameel K, Suhail M. Pattern, and profile of alopecia areata in Pakistan. J Pak Assoc Dermatol. 2009;19(3):136-40.

10. Simakou T, Butcher JP, Reid S. Alopecia areata: A multifactorial autoimmune condition. J Autoimmun. 2019;98:74-85.

11. Paus $R$, Bertolini $M$. The role of hair follicle immune privilege collapse in alopecia areata: status and perspectives. J Investig Dermatol Symp Proc. 2013;16(1):25-7.

12. Nanda A, Al-Fouzan AS, Al-Hasawi F. Alopecia areata in children: Clinical profile. Pediatr Dermatol. 2002;19(6):482-6.

13. Naveed S, Hmeed A, llyas H, Saleem A, Kanwal H, Ali E, Iqbal, R. Prevalence and consequences of hair fall, survey-based study in Karachi. Mintage J Pharm Med Sci. 2015;1:11-20.

14. Javed M, Jairamani C. Pediatric dermatology: an audit at Hamdard University Hospital, Karachi. J Pak Assoc Dermatol. 2017;16(2):93-6.
15. Wesserman D, Guzman-Sanchez DA, Scott K, McMichael A. Alopecia areata. Int J Dermatol. 2007; 46(2):121-31.

16. Li AW, Antaya RJ. Successful treatment of pediatric Alopecia Areata of scalp using topical bimatoprost. Pediatr Dermatol. 2016;33(5):282-3.

17. Welsh O. Phototherapy for alopecia areata. Clin Dermatol. 2016;34(5):628-32.

18. Mesinkovska NA. Emerging unconventional therapies for alopecia areata. J Investig Dermatol Sympo Proc.2018;19(1):323.

19. Liu LY, Craiglow BG, Dai F, King BA. Tofacitinib for the treatment of severe alopecia areata and variants: A study of 90 patients. J Am Acad Dermatol. 2017;76(1):22-8.

20. Wang ECE, Dai Z, Christiano AM. Novel therapies for alopecia areata: The era of rational drug development. J Allergy Clin Immunol. 2018;141(2) 499-504.

21. Olsen E, Hordinsky M, McDonald-Hull S, Price V, Roberts J, Shapiro J, Stenn K. Alopecia areata investigational assessment guidelines. J Am Acad Dermatol.1999;40(2):242-6.

22. Polat AK, Yesilova Y, Alatas ET, Belli AA, Dogan G, Picakciefe M. Prevalence of skin diseases of the pediatric population in the Southeastern Anatolia, Turkey. Med Sci. 2018;7(3):664-7.

23. Tan E, Tay YK, Goh CL, Chin GY. The pattern and profile of alopecia areata in Singapore - a study of 219 Asians. Int J Dermatol. 2002;41(11):748-53.

24. Sharma VK, Kumar B, Dawn G. A clinical study of childhood alopecia areata in Chandigarh, India. Pediatr Dermatol. 1996;13(5):372-7.

25. Nellist CC. [internet]. Alopecia areata has female predominance more severe types common in boys. Pediatr News.2018. https://www.mdedge.com/pediatrics/article/162287/hairnails/alopecia-areata-has-female-predominance-more-severe-types

26. Ahmed, I, Nasreen S, Bhatti R. Alopecia areata in children. J Coll Physicians Surg Pak.2007;17(10):587-90.

27. Narla S, Silverberg Jl. Association between atopic dermatitis and autoimmune disorders in US adults and children: A crosssectional study. J Am Acad Dermatol. 2019;80(2):382-89.

28. Xiao FL, Yang S, Liu JB, He PP, Yang J, Cui Y, Yan KL, Gao M, Liang YH, Zhang XJ. The epidemiology of childhood alopecia areata in China: a study of 226 patients. Pediatr Dermatol. 2006;23(1):13-8.

\section{AUTHORSHIP CONTRIBUTION}

\begin{tabular}{|l|l|}
\hline $\begin{array}{l}\text { Dr. Muhammad Arif Maan } \\
\text { Associate Professor, Dermatology, Faisalabad } \\
\text { Medical University, Faisalabad Pakistan }\end{array}$ & $\begin{array}{l}\text { Study Design, Sample } \\
\text { Collection, Manuscript } \\
\text { Editing }\end{array}$ \\
\hline $\begin{array}{l}\text { Dr. Ayesha Abrar } \\
\text { Medical Officer of Dermatology, Ghulam } \\
\text { Muhammad General Hospital, Faisalabad } \\
\text { Pakistan }\end{array}$ & $\begin{array}{l}\text { Sample Collection, } \\
\text { Data Documentation }\end{array}$ \\
\hline $\begin{array}{l}\text { Dr. Hoda Zahoor } \\
\text { MPhil Scholar, Biochemistry }\end{array}$ & Data Analysis, Results \\
University of Agriculture, Faisalabad Pakistan & Interpretation, \\
\hline $\begin{array}{l}\text { Dr. Fatma Hussain } \\
\text { Associate Professor, Biochemistry, University } \\
\text { of Agriculture, Faisalabad Pakistan }\end{array}$ & Study Design, Data \\
\hline $\begin{array}{l}\text { Dr. Shahid Javaid Akhtar } \\
\text { Professor, Head of Dermatology, Faisalabad } \\
\text { Medical University, Faisalabad Pakistan }\end{array}$ & Writeup, Editing \\
\hline
\end{tabular}

